\title{
ОСОБЛИВОСТІ РОЗРАХУНКУ ЕЛЕМЕНТІВ 3 ДЕРЕВИНИ ПРИ ПРЯМОМУ ПОПЕРЕЧНОМУ ЗГИНІ ЗА ДЕФОРМАЦІЙНОЮ МЕТОДИКОЮ
}

\section{CALCULATION PECULIARITIES OF WOODEN ELEMENTS USING DEFORMATION METHOD FOR TRANSVERSE BENDING}

\author{
Бабич С.М., д.Т.н., проф., Гомон С.С., к.т.н., проф., (Національний \\ університет водного господарства та природокористування, Рівне)
}

\begin{abstract}
Babich E.M., T.Sc.D., professor, Gomon S.S, Ph.D., professor (National University of Water and Environmental Engineering, Rivne)
\end{abstract}

Анотація. Розглянуто особливості методики розрахунку нормальних розрахункових перерізів елементів з цільної та клеєної деревини при поперечному прямому згині за деформаційною моделлю.

Summary. Timber is the oldest building material, which, due to its restorative, ecological cleanliness and aesthetics, strengthens its position in the construction industry market. At present, all calculations of constructions of solid and glued wood for different types of loads, according to the operating norms of different countries, are carried out by the method of boundary states, which are based on elastic wood work.

The methodology of calculation of elements from solid or glued wood for working on a pure transverse bend using a strain model based on a series of experimental studies and analysis of their work is developed. For the developed method, the concept of "calculated cross-section" is used, which involves the formation of a fold in fron tof a destructive state and four stages of a strained-deformed stateof a timber element operating on a straight transverse bend.

The proposed method of deformation model for the calculation of elements from wood is based on the use of complete diagrams of the mechanical state of the material under longitudinal compression, including the downward deformation branch at the critical stage of work.

Deformations in the calculated cross-section are determined by the curvature at any point of the section and taking into account the smallness of their values.

On the basis of deformations, the stress in a normal cross-section is described by two functions in three different sections: the first sectionis the tensile region from the bottom of the element to the neutral line; the second section - from the neutral line to the maximum stress in the compressed zone; the third section - from the maximum stress in the compressed zone to the top of the element.

The method for calculating solid and glued wood beams using a deformation model is developed. This method takes into account the distribution of stresses in height of the compressed and stretched zones of the calculated cross-section and provides for the formation of folds in the compressed zone of the element in the area of pure bending. It 
also fully allows to examine and experimentally investigate the stress-strain state under load of glued beams at different stages of their work.

Ключові слова:деревина, розрахунок, деформаџї̈, напруження.

Keywords:timber, ccalculation, deformations, tension.

Вступ. В сучасних умовах розрахунок дерев'яних елементів суцільного поперечного перерізу, які працюють на згин, проводять за досить спрощеною недосконалою методикою $[1,2]$. Вона базується на експериментально-теоретичних твердженнях, запропонованих у 50-х роках XX століття [3], виходячи 3 кусково-лінійної залежності між напруженнями та деформаціями ( $\sigma-u)$ (рис. $1 a$ ) та тезах-догмах:

- деревина працює, як абсолютно пружний матеріал;

- модулі пружності рівні в розтягнутій і стиснутій зонах:

- прийнята прямолінійна залежність розподілення напружень по всій висоті згинального елемента;

- положення нейтральної площини незмінне;

- введено поняття міцності деревини на згин.

Але при цьому не зважали на те, що міцність деревини на розтяг удвічі перевищує міцність на стиск. Лінійне визначення рівномірного зростання напружень по висоті перерізу в обох зонах можливе лише в межах умовної пропорційності. Хоча і на цій стадії роботи зростання еластичних деформацій до умовної межі пропорційності не є лінійним за зростання короткочасного навантаження (рис.1б.). За рівності деформацій в стиснутих та розтягнутих волокнах поперечного перерізу балки напруження в цих шарах різні. А внаслідок нелінійного зростання повздовжніх відносних деформацій стиску деревини, як показали багаточисленні експерименти, проходить зміщення положення нейтральної лінії вже на початковій стадії напруженого стану розрахункового поперечного перерізу $[4,5,6]$. Зміна положення нейтральної площини (в розрахунковому перерізі - нейтральної лінії) між стиснутою та розтягнутою зонами (рис.2) в сторону розтягнутої зони призводить до неможливого використання для простих поперечних перерізів (прямокутник, круг), які найчастіше зустрічаються при проектуванні конструкцій 3 деревини, геометричних характеристик перерізів. 

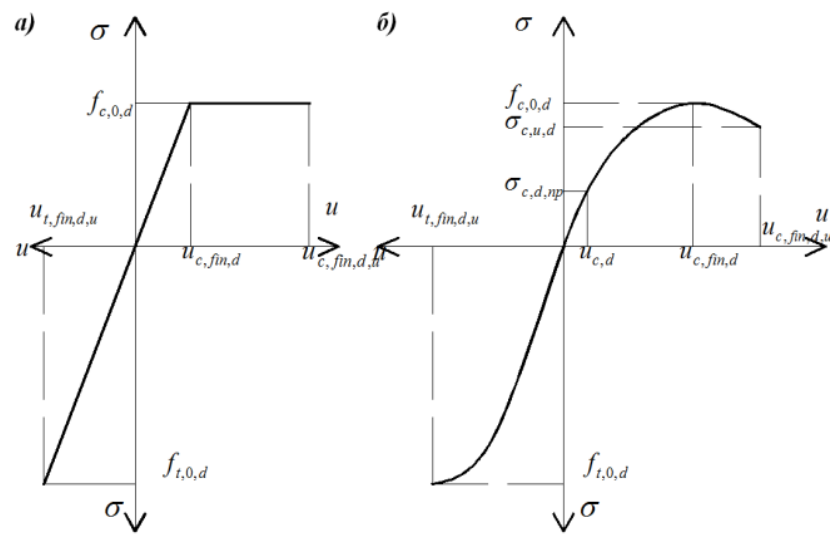

Рис.1- Діаграми деформування деревини $(\sigma-u)$ за стиску та розтягу

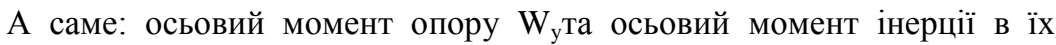
класичному визначенні опору матеріалів, так як положення нейтральної лінії поперечного перерізу не співпадає з положенням осьової лінії цього перерізу, яка проходить по центру ваги.

До того ж розрахунковий опір деревини $f_{m, d}$, що використовується у формулі (1), при розрахунку на згин $є$ встановлена величина, яка знаходиться не $з$ прямого експериментального визначення, а 3 пропозицій [3] за виразом (2)

$$
\begin{array}{r}
\frac{\sigma}{f_{m, d}} \leq 1 . \\
R_{u}=R_{c} \frac{3 \frac{R_{t}}{R_{c}}-1}{\frac{R_{t}}{R_{c}}+1},
\end{array}
$$

де $f_{m, d}=R_{u}$ - розрахунковий опір деревини згину; $R_{c}$ - розрахунковий опір деревини стиску вздовж волокон; $R_{t}$ - розрахунковий опір деревини розтягу вздовж волокон.

Основна частина. Несуча здатність елементів конструкцій 3 деревини в багатьох випадках визначається міцністю ділянок, які працюють в умовах складного неоднорідного напруженого стану. 


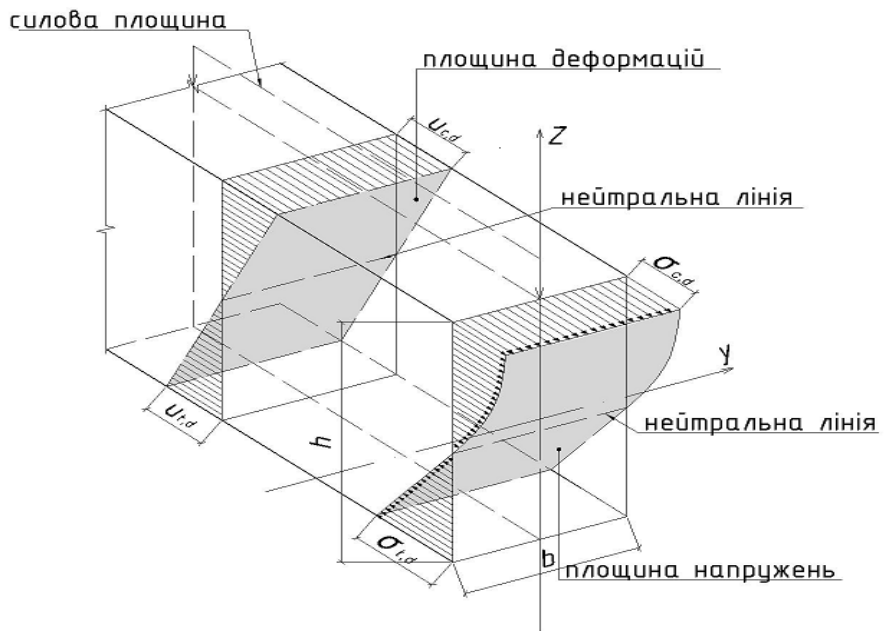

Рис.2. Розподіл деформацій і напружень у розрахунковому поперечному перерізі елемента з деревини за поперечного згину

Так для анізотропних матеріалів несуча здатність елементів конструкцій з деревини на думку С.К. Ашкеназі [7], Г.А. Генієва [8], С.М. Знаменського [9], Ю.М. Іванова [10], С.М. Кваснікова [11], В.З. Кліменка [12], В.В. Фурсова [13], Медсєна [14] та інших визначається міцністю окремих ділянок. Для елементів, що працюють на поперечний прямий чи косий згин, однією з цих ділянок $є$ нормальний розрахунковий поперечний переріз. У розрахунках конструкцій з деревини, як правило, та в чинних нормах використовується поперечний переріз зі щільної суцільної деревини. Такий підхід по встановленню розрахункового поперечного перерізу конструкцій 3 деревини має ряд недоліків. В будівельній механіці 3 цим терміном пов'язують i умови рівноваги відрізаного перерізу елемента, і припущення по розподілу деформацій та напружень в цьому перерізі, і критерій вичерпання несучої здатності. Отже, для розрахунків за нормальний розрахунковий поперечний переріз необхідно приймати ділянку згинального елемента 3 деревини, де утворюється складка в стиснутій зоні в стадії роботи перед руйнуванням. Тобто складка, як найслабкіша ділянка, і $є$ тим визначальним критерієм, яким необхідно користуватись 3 погляду опору матеріалів. Переріз зі складкою часто в елементі з деревини в передруйнівному стані візуально важко помітити через миттєвість руйнування конструкції.

Для розрахункового поперечного перерізу зі складкою в стиснутій зоні елемента з деревини можна застосовувати відомі закони розподілення деформацій по висоті, як в стиснутій, так і в розтягнутій зонах, тому що 
можна використати апарат нескінченно малих величин. Такий апарат можна використовувати за умови нерозривності функції в околиці точки перерізу, яку розглядаємо. Використання такого апарату в механіці твердого тіла обумовлюється гіпотезою суцільності і однорідності матеріалу [15]. В перерізі зі складкою в стиснутій зоні елемента 3 деревини всі ці умови практично виконуються. Отже, розрахунковий поперечний переріз являє собою модель, яка відображає закономірності деформування та руйнування елемента $з$ деревини.

За розрахункову аналітичну залежність для опису криволінійної діаграми фізичного стану деревини $\sigma_{d}-u_{d}$ за повздовжнього стиску від початку навантаження і до руйнування прийнята функція у вигляді поліному другого степеня на основі пропозицій, які наведені в роботах [16, $17,18]$ і приведені формулою (3). Дана функція досить добре описує фізичний стан роботи деревини сосни за осьового стиску вздовж волокон $\mathrm{i}$ враховує як висхідну вітку, так і першу ділянку спадної вітки діаграми.

$$
\sigma_{c, d}=k_{1} u_{c, d}+k_{c} u_{c, d}^{2}
$$

Епюри напружень $\sigma$ в залежності від відносних деформацій $u$ для нормального розрахункового перерізу дерев'яного згинального елемента виразимо двома функціями на різних ділянках.

Напруження стиснутої зони розрахункового перерізу опишемо криволінійною функцією (3), яка визначає напруження, що виникають на двох ділянках по висоті стиснутої зони дерев'яного елемента в межах від 0 до $z_{c}$.

В той же час у розтягнутій зоні за збільшення зовнішнього навантаження зростання відносних деформацій проходить лінійно по висоті розрахункового поперечного перерізу. В найбільш віддалених від нейтральної лінії волокнах деревини за зростання напружень, близьких до руйнівних, мала б проявлятися здатність наростання пластичних деформацій. Але через сумісну роботу всіх шарів деревини в перерізі менш напружені волокна деревини стримують цей процес.

Тому, за розрахункову аналітичну залежність для опису прямолінійної діаграми фізичного стану деревини $\sigma_{d}-u_{d}$ за повздовжнього розтягу від початку навантаження i до руйнування, доцільно приймати другу функцію - лінійну, яка наведена формулою (4).

$$
\sigma_{t, d}=E \cdot u_{t, d} .
$$


При поступовому збільшенні навантаження на елемент від початку завантаження i до руйнування напружено-деформований стан балки змінюється: збільшуються напруження у стиснутій та розтягнутій зонах. При цьому змінюється характер розподілу напружень, утворюються та розвиваються складки в глибину стиснутої зони. В роботі елементів 3 деревини 3 використанням повних діаграм механічного стану матеріалу проходять чотири характерні стадії напружено-деформованого стану [19, 20].

Надійність експериментальних даних за діаграмами деформування деревини за дії постійного приросту градієнта деформацій та аналітичного апарату встановлення коефіцієнтів поліномів другого степеня разом 3 трансформацією фізичного стану матеріалу у фізичний стан елемента, дають можливість розробити методику розрахунку напруженодеформованого стану елементів 3 деревини при роботі на згин для стиснутої зони прямокутного перерізу (рис. 3).

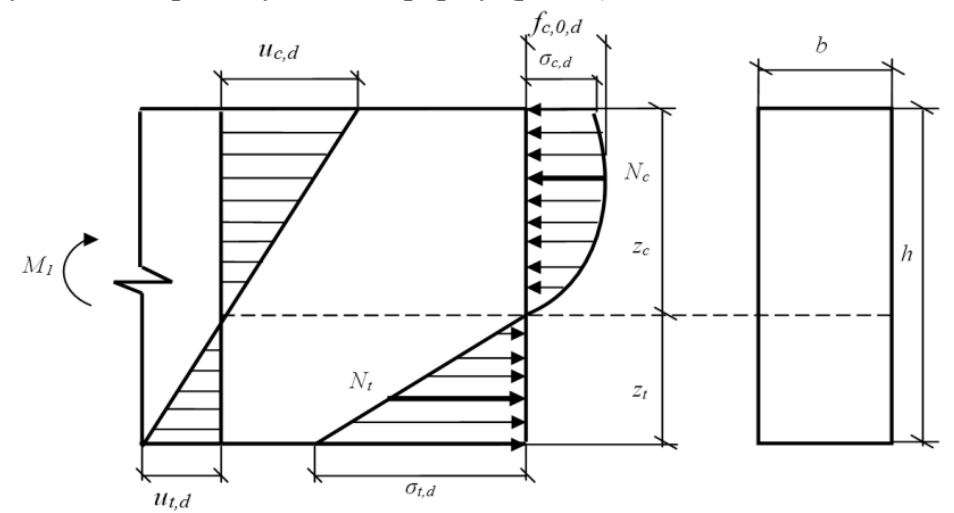

Рис.3. Поперечний переріз, відносні деформації та внутрішні зусилля в прямокутному перерізі з деревини.

За фіксованих значень висоти стиснутої зони деревини $z_{1}=z_{c}$ та деформацій крайнього стиснутого волокна деревини при $u_{c, d}=u_{c, d, 1}$, деформацій крайнього розтягнутого шару деревини $u_{t, d}=u_{t, d, 1}$ рівняння рівноваги зовнішніх і внутрішніх зусиль у нормальному перерізі мають вигляд

$$
\begin{gathered}
\sum M_{t . n .}=0 ; \\
M_{1}=M_{c, d, 1}+M_{t, d, 1} ;
\end{gathered}
$$




$$
\begin{gathered}
\sum N=0 ; \\
N_{c, d, 1}=N_{t, d, 1} .
\end{gathered}
$$

Виходячи 3 того, що деформації в перерізі, які можливо визначити через кривину елемента для будь-якої точки перерізу з врахуванням малої величини їх значень, на всіх стадіях завантаження можуть бути визначені за формулами:

$$
\begin{aligned}
& u_{t, d}=\frac{1}{\rho} z_{t} ; \\
& u_{c, d}=\frac{1}{\rho} z_{c},
\end{aligned}
$$

Враховуючи вище наведене, функції (3) та (4) матимуть вигляд

$$
\begin{aligned}
\sigma_{t, d} & =f_{1}(u)=E_{t} \cdot \frac{1}{\rho} z_{t}, \\
\sigma_{c, d}=f_{2}(u) & =k_{1} \frac{1}{\rho} z_{c}+k_{c}\left(\frac{1}{\rho}\right)^{2} z_{c}^{2},
\end{aligned}
$$

Зусилля розтягу в даному нормальному розрахунковому перерізі елемента з деревини буде дорівнювати:

$$
N_{t}=b \int_{0}^{z_{t}} f_{1}(u) d z=b \int_{0}^{z_{t}} E_{t} \frac{1}{\rho} z_{t} d z=b E_{t} \frac{1}{\rho} \cdot \frac{z_{t}^{2}}{2} .
$$

Зусилля стиску в цьому ж розрахунковому перерізі буде дорівнювати:

$$
N_{c}=b \int_{0}^{z_{c}} f_{2}(u) d z=b \int_{0}^{z_{c}}\left(k_{1} \frac{1}{\rho} z_{c}+k_{c}\left(\frac{1}{\rho}\right)^{2} z_{c}^{2}\right) d z=b\left(k_{1} \frac{1}{\rho} \cdot \frac{z_{c}^{2}}{2}+k_{c}\left(\frac{1}{\rho}\right)^{2} \frac{z_{c}^{3}}{3}\right) .
$$

Згинальний момент відносно нейтральної лінії для розтягнутої зони в данному розрахунковому перерізі буде дорівнювати:

$$
M_{t}=\int_{0}^{z_{t}} f_{1}(u) b z_{t} d z=\int_{0}^{z_{t}} b E_{t} \frac{1}{\rho} z_{t}^{2} d z=b E_{t} \frac{1}{\rho} \cdot \frac{z_{t}^{3}}{3} .
$$


Згинальний момент відносно нейтральної лінії стиснутої зони в данному нормальному розрахунковому перерізі визначиться

$$
M_{c}=\int_{0}^{z_{c}} f_{2}(z) d z b=b \int_{0}^{z_{c}}\left(k_{1} \frac{1}{\rho} z_{c}^{2}+k_{c}\left(\frac{1}{\rho}\right)^{2} z_{c}^{3}\right) d z=b\left(k_{1} \frac{1}{\rho} \cdot \frac{z_{c}^{3}}{3}+k_{2}\left(\frac{1}{\rho}\right)^{2} \frac{z_{c}^{4}}{4}\right) .
$$

Для визначення згинального моменту за формулою (6), який може сприйняти елемент з деревини, необхідно значення відносних деформацій деревини, за яких виконується умова рівноваги внутрішніх зусиль $N_{c}=N_{\mathrm{t}}$, підставити у рівняння (15) та (16).

Висновок. Запропонована методика деформаційної моделі розрахунку елементів 3 деревини повною мірою дозволяє розглянути та розрахувати напружено-деформований стан балок під навантаженням із цільної та клеєної деревини на різних стадіях їх роботи.

\section{References}

1. Design of timber structures. Eurocode 5. Part 1.1. General rules and rulesforbuildings(1995), 124.

2. Konstruktsiyi budynkiv i sporud. Derev"yani konstruktsiyi. Osnovni polozhennya. DBN V.2.6-161:2017. Ukrarkhbudinform, 2017. 119s

3. Kochenov V.M. Nesushchaya sposobnost' élementov y soedynenyy derevyannykh konstruktsyy. Moskva: Hosudarstvennoe yzdatel'stvo. 1953. 320 s.

4. Gomon S.S. , Yatsuk V.O. Rozrakhunok elementiv konstruktsiy z derevyny za roboty na poperechnyy $z$.hyn $z$ urakhuvannyam povnoyi diahramy deformuvannya materialu. Resursoekonomni materialy, konstruktsiyi, budivli ta sporudy", NUVHP.Vypusk 23. Rivne,2012. S. 178-188.

5. Gomon S.S., Pavlyuk A.P., Polishchuk M.V. Zmina polozhennya neytral'noyi liniyi balok $\mathrm{z}$ tsil'noyi derevyny za kosoho $\mathrm{z}$ hynu $\mathrm{v}$ zalezhnosti vid kharakteru obpyrannya i prykladennya navantazhennya. Mistobuduvannya ta terytorial'ne planuvannya: Naukovo-tekhnichnyy zbirnyk . - K., KNUBA, 2016. -Vyp.61.- S. 120127.

6. Betts S.C., Miller T. H., Cupra B. Location of the neutral axis in wood beams: A preliminary study.Wood Material Science and Engineering, 5, 2010.P. 173-180.

7. Ashkenazi Ye.K. Anizotropiya prochnosti drevesnykh i sinteticheskikh materialov: avtoref. diss. ... d-ratekhn. nauk: 05.23.01. Leningrad, 1969.

8. Geniyev G.A. O kriterii prochnosti drevesiny pri ploskom napryazhennom sostoyanii. Stroitel'naya mekhanika i raschet sooruzheniy. 1981. № 3. S. 15-20.

9. Znamenskiy Ye.M. Sovershenstvovaniye normirovaniya raschetnykh kharakteristik elementov derevyannykh konstruktsiy. Razrabotka i sovershenstvovaniye derevyannykh konstruktsiy. Sbornik nauchnykh trudov, TSNIISK im. V.A. Kucherenko. Moskva, 1989. S. 36-47.

10. Ivanov YU.M. K voprosu issledovaniya skladki razrusheniya drevesiny pri szhatii vdol' volokon. Sb.: Trudy instituta lesa. Moskva: AN SSSR, 1953.T.9. S. 115121. 
11. Kvasnikov Ye.N. O napryazhennom sostoyanii drevesiny pri izgibe. Inzhenernyyekonstruktsii: KHKHKH konferentsiya. Leningrad: LISI, 1972. S. 106114.

12. Klimenko V.Z. Metodicheskiye rekomendatsii po raschetu stroitel'nykh konstruktsiy iz kleyenoy drevesiny s uchetom slozhnogo napryazhennogo sostoyaniya materiala. Kiyev: KISI, 1998. 50 s.

13. Fursov V.V. K raschetu kleyenoy drevesiny v usloviyakh slozhnogo napryazhenogo sostoyaniya. Sovremennyye konstruktsii iz metalla i drevesiny: Sbornik nauchnykh trudov. Odessa, 1999g. S. 216-221.

14. Medsen B. Duration of load tests for dry lumber subjected to shear. Forest Products J., 1975, Vol. 25.№ 10. P. 44-52.

15. Filin A.P. Prikladnayamekhanika tverdogo deformiruyemogotela: uchebnoyeposobiye. Tom 2. Moskva: Nauka, 1978.616s.

16. Lukash P.A. Osnovy nelineynoy stroitel'noy mekhaniki. Moskva: Stroyizdat, 1978. 208s.

17. Pyatikrestovskiy K. P. Silovoye soprotivleniye prostranstvennykh derevyannykh konstruktsiy pri kratkovremennykh i dlitel'nykh nagruzkakh avtoref.dis. ... dokt.tekhn.nauk: 05.23.01. Moskva, 2012.44 s.

18. Gomon S., Gomon S., Gomon P., Shkirenko S. The Basis of the Deformation Method for Calculating of Elements from Wood under Cross-Section Bending.International Journal of Engineering \& Technology. 2018. Vol.7 (4.8). P. 109114.

19. Gomon S.S. Stadiyi napruzheno-deformovanoho stanu normal'nykh pereriziv roboty derevyny na $\mathrm{z} \cdot \mathrm{hyn}$. Resursoekonomni materialy, konstruktsiyi, budivli ta sporudy. Rivne: NUVHP, 2011. Vyp. 21. S. 176-180.

20. Gomon S., Gomon S., Karavan V., Gomon P., Sobczak-Piastka J. Investigation of solid and glued wood on the effect of variables of low-cycle repeated loads. AIP Conference Proceedings 2077, 020020 (2019). P. 1-6. htts://doi.org/10.1063/1.5091881.

\section{Список використаної літератури}

1. Design of timber structures.Eurocode 5.Part 1.1. General rules and rules for buildings (1995), 124.

2. Конструкції будинків і споруд. Дерев'яні конструкції. Основні положення. ДБН В.2.6-161:2017. Укрархбудінформ, 2017. 119с

3. Коченов В.М. Несущая способность элементов и соединений деревянных конструкций. Москва: Государственное издательство. 1953. 320 с.

4. Гомон С.С. , Яцук В.О. Розрахунок елементів конструкцій з деревини за роботи на поперечний згин 3 урахуванням повної діаграми деформування матеріалу. Ресурсоекономні матеріали, конструкції, будівлі та споруди", НУВГП.Випуск 23. Рівне,2012. С. 178-188.

5. Гомон С.С., Павлюк А.П., Поліщук М.В. Зміна положення нейтральної лінії балок 3 цільної деревини за косого згину в залежності від характеру обпирання i прикладення навантаження. Містобудування та територіальне планування: Науково-технічний збірник . - К., КНУБА, 2016. -Вип.61.- С. 120-127.

6. Betts S.C., Miller T. H., Cupra B. Location of the neutral axis in wood beams: A preliminary study.Wood Material Science and Engineering, 5, 2010.P. 173-180.

7. Ашкенази Е.К. Анизотропия прочности древесных и синтетических материалов: автореф. дисс. ... д-ратехн. наук: 05.23.01. Ленинград, 1969. 
8. Гениев Г.А. О критерии прочности древесины при плоском напряженном состоянии. Строительная механика и расчет сооружений. 1981. № 3. С. 15-20.

9. Знаменский Е.M. Совершенствование нормирования расчетных характеристик элементов деревянных конструкций. Разработка и совершенствование деревянных конструкций. Сборник научных трудов, ЦНИИСК им. В.А. Кучеренко. Москва, 1989. С. 36-47.

10. Иванов Ю.М. К вопросу исследования складки разрушения древесины при сжатии вдоль волокон. Сб.: Труды института леса. Москва: АН СССР, 1953.T.9. С. $115-121$.

11. Квасников Е.Н. О напряженном состоянии древесины при изгибе. Инженерныеконструкции: XXX конференция. Ленинград: ЛИСИ, 1972. С. 106114.

12. Клименко В.3. Методические рекомендации по расчету строительных конструкций из клееной древесины с учетом сложного напряженного состояния материала. Киев: КИСИ, 1998. 50 с.

13. Фурсов В.В. К расчету клееной древесины в условиях сложного напряженого состояния. Современные конструкции из металла и древесины: Сборник научных трудов. Одесса, 1999г. С. 216-221.

14. Medsen B. Duration of load tests for dry lumber subjected to shear. Forest Products J., 1975, Vol. 25.№ 10. P. 44-52.

15. Филин А.П. Прикладнаямеханика твердого деформируемоготела: учебноепособие. Том 2. Москва: Наука, 1978.616с.

16. Лукаш П.А. Основы нелинейной строительной механики. Москва: Стройиздат,1978. 208c.

17. Пятикрестовский К. П. Силовое сопротивление пространственных деревянных конструкций при кратковременных и длительных нагрузках автореф.дис. ... докт.техн.наук: 05.23.01. Москва, 2012.44 с.

18. Gomon S., Gomon S., Gomon P., Shkirenko S. The Basis of the Deformation Method for Calculating of Elements from Wood under Cross-Section Bending.International Journal of Engineering \& Technology. 2018. Vol.7 (4.8). P. 109114.

19. Гомон С.С. Стадії напружено-деформованого стану нормальних перерізів роботи деревини на згин. Ресурсоекономні матеріали, конструкції, будівлі та споруди. Рівне: НУВГП, 2011. Вип. 21. С. 176-180.

20. Gomon S., Gomon S., Karavan V., Gomon P., Sobczak-Piastka J. Investigation of solid and glued wood on the effect of variables of low-cycle repeated loads.AIP Conference Proceedings 2077, 020020 (2019). P. 1-6. htts://doi.org/10.1063/1.5091881. 